\title{
The Impact of New Nurses' Organizational Immersion and Job Burnout on Intent to Leave: Nurses Under 6 Months in Work Period
}

\section{일개병원 신입간호사의 조직몰입과 직무소진이 이직의도에 미치는 영향: 6개월 이하 간호사를 대상으로}

\author{
Young-Ju Jee ${ }^{1}$, Moon-Young Choi ${ }^{2}$ \\ 지영주1, 최문영2 \\ ${ }^{1}$ Associate Professor, College of Nursing, Kyungnam University, Changwon, \\ jeeyoungju@kyungnam.ac.kr \\ ${ }^{2}$ Nurse, Samsung Changwon Hospital, Changwon, ansdud0403@naver.com \\ Corresponding author: Moon-Young Choi
}

\begin{abstract}
The purpose of this study is to identify the effects of Organizational Immersion and Job Burnout on intent to leave in New nurses. Data were collected from November 23, 2019 to August 31, 2020, self-questionnaires from New nurses. The collected data were analyzed using t-test, one way ANOVA, Scheffé test, Pearson's correlation coefficient, and Simultaneous Multiple regression. The most influential factor in turnover intention of new nurses is organizational immersion $(\beta=-.62, p<.001)$ followed job burnout $(\beta=.19, \mathrm{p}=.043)$. The analysis showed that the degree regression model for turnover intention was statistically significant $(\mathrm{F}=36.52, \mathrm{p}<.001)$, which was the explanatory power of $52 \%$. Based on the results of this study, it is considered necessary to develop a program to increase the organizational commitment of new nurses and to apply measures to reduce job burnout in order to reduce the turnover intention of new nurses. Since this study was conducted with 68 new nurses in a hospital, there is a limit to generalizing the research results.
\end{abstract}

Keywords: Organizational Immersion, Job Burnout, Turnover Intention, New Nurses

요약: 본 연구의 목적은 신입간호사의 조직몰입과 직무소진이 이직의도에 미치는 영향을 규명하는 것이다. 본 연구의 자료수집을 위해 신입간호사를 대상으로 2019년 11월 11일부터 2020년 8월 31일까지 자기보고식 설문을 실시하였다. 수집된 자료는 t-test, One way ANOVA, Schéff test, 피어슨 상관계수(Pearson's correlation coefficient) 및 Simultaneous multiple regression으로 분석하였다. 신입간호사의 이직의도에 가장 영향력을 크게 미치는 요인은 조직몰입( $\beta=-.62, \boldsymbol{p}<.001)$ 이었고, 그 다음으로는 직무소진 $(\beta=.19, \mathrm{p}=.043)$ 순이었다. 분석결과 이직의도 회귀모형은 통계적으로 유의하였고 $(\mathrm{F}=36.52, \mathrm{p}<.001)$, 설명력은 $52 \%$ 였다. 본 연구의 결과를 바탕으로 신입간호사의 이직의도를 감소시키기 위해서는 신입간호사의 조직몰입을 높이기 위한 프로그램을 개발하고 직무소진을 낮추기 위한 방안을 적용하는 것이 필요할 것으로 생각된다. 본 연구는 일개병원 신입간호사 68명을 대상으로 하였으므로 연구결과를

Received: December 18, 2020; $1^{\text {st }}$ Review Result: January 29, 2021; $2^{\text {nd }}$ Review Result: March 20, 2021 Accepted: April 30, 2021 
일반화하기에는 제한이 있다.

핵심어: 조직몰입, 직무소진, 이직의도, 신입간호사

\section{1. 서론}

\section{1 연구의 필요성}

보건의료사업은 노동집약적인 사업이며, 특히 간호사는 병원 인력 전체에서 $63.6 \%$ 로 큰 비중을 차지하고 있다[1]. 보건의료사업에서 간호사는 국민에게 의료서비스를 안전하고 효과적으로 제공하고, 건강을 옹호하는 핵심적이고 중요한 전문 인력이다[2]. 우리나라는 의료기관의 의료이용량에 대비하여 간호사의 법정 정원 부족이라는 수급 추계 결과를 토대로 2007년 이후 간호사 부족에 대한 문제가 지속적으로 제기되었다[3][4]. 간호사 부족 문제를 해결하기 위한 지금까지의 간호 인력 수급대책은 간호학과 정원확대를 통해 배출되는 간호사의 수를 늘리는 방식이었다. 그 결과 국내 인구 천 명 당 면허 및 자격을 가진 간호인력 평균 19.16 명과 $\mathrm{OECD}$ 국가 평균 12.52 명을 비교해 보면 국내 간호인력 수가 더 높으나, 국내 활동 간호인력은 5.94명으로 $\mathrm{OECD}$ 국가 평균 8.81 명 보다 낮으며, 국내 의료기관에서 활동하는 간호사 수는 $\mathrm{OECD}$ 평균의 약 $53.8 \%$ 수준이다[3][4].

국내의 전체 면허 간호사의 수는 늘어나고 있는 반면에 여전히 간호 인력 부족 문제가 나타나는 이유 중 하나는 높은 이직률 때문이다. 신입간호사의 경우 채용인원의 $45.5 \%$ 가 사직하는 것으로 나타나 높은 사직율을 보였으며[5], 간호사는 사직을 하더라도 늘 취업지가 존재하고 있다. 날이 갈수록 심각한 실업률에 직면한 생산계층 비해 간호직은 넓은 취업문과 고수익의 직장이므로 현재 직장에서 사직을 한다는 것이 휴직 상태이기보다는 이직으로 연결되는 경우가 많다. 그러나 사직과 이직으로 인한 불안전한 병원 인력 환경은 국가적으로 의료서비스 질을 떨어뜨리고 전문의료인에 의한 서비스 제공을 불가하게 하는 요인으로 작용한다. 신입간호사의 이직 영향요인을 파악하고 이직률을 낮추기 위한 방안이 필요하다. 이직의도와 이직률이 동일하지는 않으나 높은 이직 의도는 이직률로 이어질 가능성이 크기 때문에 간호사 인력난 해소를 위해 신입간호사의 이직의도에 영향을 미치는 요인을 확인해야 할 필요가 있다.

신입간호사 이직의도와 긍정적인 상관관계를 가진 요인으로는 총 임상경력, 현 의료기관에서의 경력, 주당 근무시간, 매월 밤 근무 수, 업무부적응, 소진, 대인관계 스트레스, 직무 스트레스가 있었다[6-9]. 반대로 신입간호사의 이직의도와 부정적인 상관관계를 가진 요인으로는 시간외 근무수당, 고충상담실, 급여만족도, 근무부서 만족도, 조직몰입, 자기 효능감, 간호조직문화, 근무 병원 병상 수, 임파워먼트, 직무만족이 있었다[6-8][10]. 간호사 이직의도 영향요인 중 조직몰입은 개인 주변의 가족 및 직업과 관련된 요소 가운데서도 가장 효과크기가 두드러지게 나타났다[11]. 신입간호사에게 있어서 직무 스트레스가 높아질수록 직무만족이 낮아지고, 직무만족이 낮으면 조직몰입이 낮아지며, 조직몰입이 낮을수록 이직의도가 높아졌다[12]. 이러한 신입간호사의 조직몰입은 이직의도에 영향을 미치는 변수 중 하나로 나타났으므로[9][13], 
신입간호사의 이직요인에 미치는 영향요인으로서 조직몰입을 중요하게 고려해야 할 필요가 있다. 이직의도를 가진 임상간호사들은 전문적인 기술 습득의 기간 부족, 과다한 업무와 관련된 피로, 잡무를 통하여 소진을 경험하였다[14]. 이러한 임상간호사의 소진경험은 간호사 본인의 신체적, 정신적 건강을 해칠뿐 아니라 업무에 대한 의욕상실 및 간호직에 대한 만족도를 저하시킬뿐만 아니라 이직의도로 이어짐을 의미한다[15]. 신입간호사는 아직 자신의 직무나 역할을 수행하는데 필요한 기술이나 지식을 효과적으로 습득하지 못하여 일반간호사보다 높은 소진감을 느끼며 신입간호사들의 직무소진은 이직의도에 영향을 미치는 요인으로 나타났다[9]. 본 연구에서는 선행연구에서 7 15개월 경력의 신입간호사보다 이직의도가 더 높았던 6개월 이하 경력의 신입간호사를 대상으로[8] 조직몰입과 소진이 이직의도에 미치는 영향을 파악하고 자 한다. 본 연구의 결과는 신입간호사의 이직의도를 낮추기 위한 프로그램 개발의 기초자료로써 기여하고자 한다.

\section{2 연구의 목적}

본 연구의 목적은 신입간호사의 조직몰입과 소진이 이직의도에 미치는 영향을 파악하는 것이며 구체적인 목표는 다음과 같다.

1) 신입간호사의 일반적 특성을 파악한다.

2) 신입간호사의 조직몰입, 소진 및 이직의도 정도를 파악한다.

3) 신입간호사의 일반적 특성에 따른 조직몰입, 소진, 이직의도의 차이를 분석한다.

4) 신입간호사의 조직몰입, 소진 및 이직의도간의 상관관계를 분석한다.

5) 신입간호사의 이직의도에 미치는 영향요인을 파악한다.

\section{2. 연구방법}

\section{1 연구설계}

본 연구는 근무경력 6개월 이하 신입간호사의 조직몰입, 직무소진 및 이직의도 정도를 살펴보고 조직몰입과 직무소진이 이직의도에 미치는 영향을 파악하기 위한 서술적 관계 조사연구이다.

\section{2 연구대상}

본 연구의 대상은 경남 $\mathrm{C}$ 시 소재의 1 개의 종합병원 일반병동과 특수부서를 포함한 간호단위에서 성별에 상관없이 경력직을 제외하고 근무경력이 6 개월 이하인 정규직 간호사 중 본 연구의 목적을 이해하고 자발적으로 연구 참여에 동의한 신입간호사 75 명을 대상으로 편의추출하여 설문조사를 실시하였다. 대상자의 수는 표본크기의 적절성을 확인하기 위하여 $\mathrm{G}^{*}$ power 3.1.7 analysis software 를 이용하여 다중회귀분석에 필요한 표본수를 산출하였다. 유의수준 .05 , 검정력 .80 , 효과크기 .15 를 기준으로 최소 표본 수는 68 명이었다. 탈락율 $10 \%$ 를 고려하여 총 75 명을 대상으로 실시하였으나 코로나로 인해 대상자 모집이 어려워 최소 표본수인 68 부를 수집 및 최종 분석하였다. 


\section{3 자료수집 방법 및 윤리적 고려}

본 연구의 자료수집은 2019년 11월 11일부터 2020년 8월 31일까지 실시하였다. 연구 연구 대상자가 근무하는 병원의 간호부에 사전 허락을 받은 후 연구 대상자를 모집하였다. 본 연구는 K대학교의 윤리심의위원회(IRB No.: 1040460-A-2019-047)의 승인을 받은 뒤 시행하였으며, 연구의 익명성과 비밀보장이 됨을 설명하였고 수집된 자료가 연구 목적 이외에는 사용되지 않음을 설명하였다. 또한 연구에 참여하지 않음으로 인하여 발생하는 불이익이 없음을 설명하였고 연구 참여 도중 언제든지 철회할 수 있음을 미리 설명하였다. 설문지 작성에 소요된 시간은 약 10 분 정도이었다.

\section{4 연구도구}

연구도구는 자기보고식 설문으로 내용은 일반적 특성 12 문항, 조직몰입 12 문항, 직무소진 22 문항, 이직의도 6 문항 등 총 52 문항으로 구성되었으며 각 도구의 개발자 및 번안자에게 도구의 사용을 승인 받았다.

\subsection{1 조직몰입}

조직몰입은 Mowday, Streers 와 Porter[16]가 개발한 척도를 정혜경[17]이 간호의 특성에 맞추어 수정, 보완한 도구를 이용하여 측정하였다. 이 측정 도구는 12 개의 문항으로 각 문항은 5점 리커트 척도로 ‘항상 그렇다' 5점에서 '전혀 그렇지 않다' 1점의 범위에 있으며 점수가 높을수록 조직몰입 정도가 높음을 의미한다. 정혜경[17]의 연구에서의 신뢰도는 Cronbach's $\alpha=.93$ 이었고 본 연구에서는 Cronbach's $\alpha=.90$ 이었다.

\subsection{2 직무소진}

직무소진은 Maslach와 Jackson[18]이 교사를 대상으로 개발한 Maslach Burnout Inventory(MBI)를 최혜윤[19]이 번안한 도구를 사용하였다. MBI의 하부영역으로 정서적 고 갈 9 문항, 비인간화 5 문항, 자아 성취감 저하 8 문항으로 총 22 문항으로 구성되어있다. 각 문항은 '전혀 없다' 0 점, ‘일 년에 한번 이하' 1점, ‘한 달에 한번 이하' 2점,

‘한 달에 몇 번 정도' 3점, ‘일주일에 한 번 정도' 4점, '일주일에 몇 번' 5점, '매일' 6점으로 리커트 척도로 측정하였다. 하위요인 중 자아 성취감 저하 $4,7,9,12,17$, $18,19,21)$ 는 역환산하여 처리하였다. 점수범위는 0 6점이며 점수가 높을수록 소진이 높은 것을 의미한다. Maslach와 Jackson[18]의 연구에서 Cronbach's $\alpha=.76$ 이었고, 최혜윤[19]의 연구에서는 Cronbach's $\alpha=.86$ 이었고, 본 연구에서는 Cronbach's $\alpha=.81$ 이었다.

\subsection{3 이직의도}

이직의도는 Mobley[20]가 개발하고 김미란[21]이 수정, 보완한 도구를 사용하였다. 이 측정도구는 총 6 문항으로 구성되어있다. 각 문항은 '전혀 그렇지 않다' 1 점, ‘그렇지 않다' 2점, ‘보통이다' 3점, ‘그렇다' 4점, ‘매우 그렇다' 5점으로 리커트 척도로 측정하였다. 잔류의도를 나타내는 문항은 역환산 처리하였다. 점수범위는 1 5점이며, 점수가 높을수록 이직의도가 높은 것을 의미한다. 김미란[21]의 연구에서 신뢰도는 
Cronbach's $\alpha=.75$ 이었고 본 연구에서는 Cronbach's $\alpha=.91$ 이었다.

\section{5 자료분석방법}

본 연구의 자료는 SPSS/WIN 18.0 프로그램을 이용하여 분석하였으며, 구체적인 내용은 다음과 같다. 1) 대상자의 일반적 특성은 백분율, 평균, 표준편차를 구하였다. 2) 대상자의 조직몰입, 직무소진, 이직의도 정도는 평균과 표준편차를 구하였다. 3) 대상자의 일반적 특성에 따른 이직의도의 정도는 Independent t-test, ANOVA, Scheffé test로 분석하였다. 4) 대상자의 조직몰입, 직무소진, 이직의도 간의 상관관계는 Pearson's correlation coefficients로 분석하였다. 5) 조직몰입, 직무소진이 이직의도에 미치는 영향은 Simultaneous multiple regression analysis로 분석하였다.

\section{3. 결과}

\section{1 대상자의 일반적 특성}

본 연구에 참여한 대상자는 총 68 명이었으며, 남자는 4 명 $(5.9 \%)$, 여자는 64 명 (94.1\%)이었다. 대상자의 연령은 평균 $23.0 \pm 1.2$ 세였다. 미혼은 67 명(68.8\%), 기혼은 1 명 $(1.5 \%)$ 이었다. 근무 개월 수는 1 개월 26 명(38.2\%), 5개월 11 명 $(16.2 \%), 4$ 개월 10 명(14.7명), 3개월 8 명(11.8\%), 2개월 7 명(10.3\%), 6개월 6명 $(8.8 \%)$ 순이었다. 부서 이동 경험은 '있다' 가 11 명(16.2\%), '없다' 가 57 명(83.8\%)였다. 간호사당 환자 수는 10 명 미만은 27명(39.7\%), ‘10 19명' 은 (27.9\%), '20 29' 명은 16명(23.5)명, ‘29명 초과' 는 6명(8.8\%) 순이었다. 교대형태는 '교대근무' 가 63명(92.6), '비교대 근무' 가 5 명(7.4\%)였다. 근무부서는 '병동'이 31명(45.6), '특수 부서'가 37명(54.4\%)이었다. 직업에 대한 만족도는 '불만족’ 이 6 명 $(8.8 \%)$, '보통' 이 34 명 $(50.0 \%)$ '만족' 이 $28(41.2 \%)$ 였다. 업무강도는 '많다' 가 2 명 $(2.9 \%)$, '적절하다' 는 47(69.1\%), '적다' 는 19 명(27.9\%)이었다. 휴일 선택권은 '그렇다' 가 36 명(52.9\%), '보통이다' 이 26명(38.2\%), ‘그렇지 않다’ 가 6명(8.8\%)이었다[Table 1].

[표 1] 일반적 특성

[Table 1] General Characteristics of Participants $(\mathrm{N}=68)$

\begin{tabular}{|c|c|c|c|}
\hline Characteristics & Categories & $\mathrm{n}(\%)$ & $\mathrm{M} \pm \mathrm{SD}$ \\
\hline \multirow{2}{*}{ Gender } & Male & $4(5.9)$ & - \\
\hline & Female & $64(94.1)$ & \\
\hline \multirow{2}{*}{ Age (Year) } & - & - & \multirow{2}{*}{$23.0 \pm 1.2$} \\
\hline \multirow{2}{*}{ Marital status } & Unmarried & $67(98.5)$ & - \\
\cline { 2 - 3 } & Married & $1(1.5)$ & \\
\hline \multirow{3}{*}{ Clinical career (Month) } & 1 & $26(38.2)$ & \multirow{2}{*}{$2.9 \pm 1.8$} \\
\cline { 2 - 3 } & 2 & $7(10.3)$ & \\
\cline { 2 - 3 } & 3 & $8(11.8)$ & \\
\hline
\end{tabular}




\begin{tabular}{|c|c|c|c|}
\hline & 5 & $11(16.2)$ & \\
\hline & 6 & $6(8.8)$ & \\
\hline \multirow{2}{*}{ Exprience of working unit change (Time) } & Yes & $11(16.2)$ & \multirow{2}{*}{-} \\
\hline & No & $57(83.8)$ & \\
\hline \multirow{4}{*}{ Number of patients per nurse } & $<10$ & $27(39.7)$ & \multirow{4}{*}{$13.4 \pm 9.3$} \\
\hline & $10 \sim 19$ & 19(27.9) & \\
\hline & $20 \sim 29$ & $16(23.5)$ & \\
\hline & $29<$ & $6(8.8)$ & \\
\hline \multirow{2}{*}{ Type of Duty } & Shift & $63(92.6)$ & \multirow{2}{*}{-} \\
\hline & Non-shift & $5(7.4)$ & \\
\hline \multirow{2}{*}{ Working department } & Ward & $31(45.6)$ & \multirow{2}{*}{-} \\
\hline & Special part & $37(54.4)$ & \\
\hline \multirow{2}{*}{ Wanted present department } & Yes & $31(45.6)$ & \multirow{2}{*}{-} \\
\hline & No & $37(54.4)$ & \\
\hline \multirow{3}{*}{ Job satisfaction } & Dissatisfied & $6(8.8)$ & \multirow{3}{*}{-} \\
\hline & Neutral & $34(50.0)$ & \\
\hline & Satisfied & $28(41.2)$ & \\
\hline \multirow{3}{*}{ Heavy workload } & A lot & 2(2.9) & \multirow{3}{*}{-} \\
\hline & Appropriated & $47(69.1)$ & \\
\hline & Little & 19(27.9) & \\
\hline \multirow{3}{*}{ Day off selection } & I don't think so & $36(52.9)$ & \multirow{3}{*}{-} \\
\hline & Be average & $26(38.2)$ & \\
\hline & That's right & $6(8.8)$ & \\
\hline
\end{tabular}

\section{2 대상자의 조직몰입, 직무소진, 이직의도 정도}

본 연구의 대상자의 조직몰입은 평균 $3.5 \pm 0.5$ 점이었고, 최소값은 2.1 점, 최대값은 5.0 점이었다. 직무소진은 평균 $2.7 \pm 0.7$ 점이었고, 최소값은 0.9 점, 최대값은 4.3 점이었다. 이직의도는 평균 $2.8 \pm 0.8$ 점이었고, 최소값은 1.0 점, 최대값은 5.0점이었다[Table 2].

[표 2] 조직몰입, 직무소진, 이직의도 정도

[Table 2] Organizational Immersion, Job Burnout and Turnover Intention $(\mathrm{N}=68)$

\begin{tabular}{|c|c|c|c|}
\hline Variables & $\mathrm{M} \pm \mathrm{SD}$ & Min & Max \\
\hline Organizational Immersion & $3.5 \pm 0.5$ & 2.1 & 5.0 \\
\hline Job Burnout & $2.7 \pm 0.7$ & 0.9 & 4.3 \\
\hline Turnover Intention & $2.8 \pm 0.8$ & 1.0 & 5.0 \\
\hline
\end{tabular}

\section{3 대상자의 일반적 특성에 따른 조직몰입, 직무소진, 이직의도의 차이}

대상자의 조직몰입은 부서 이동 경험 $(\mathrm{t}=-3.03, \mathrm{p}=.003)$, 희망부서 여부(t=2.49, $\mathrm{p}=.015)$, 직업만족도 $(\mathrm{F}=13.71, \mathrm{p}<.001)$, 업무강도 $(\mathrm{F}=4.27, \mathrm{p}=.018)$ 및 휴일 선택권 $(\mathrm{F}=4.35, \mathrm{p}=.017)$ 에서 
유의한 차이가 있었다. 사후검정 결과 조직몰입은 직업만족도가 높을수록, 업무강도가 적절한 경우보다는 낮은 경우에, 낮은 경우보다는 높은 경우에서 높았다. 또한 조직몰입은 휴일 선택권이 보통인 경우보다 전혀 선택권이 없을수록 더 높았다. 대상자의 직무소진은 근무부서 $(\mathrm{F}=1.16, \mathrm{p}=.014)$, 직업만족도 $(\mathrm{F}=3.90, \mathrm{p}<.001)$ 및 업무강도 $(\mathrm{F}=8.18, \mathrm{p}=.001)$ 에 따라 유의한 차이가 있었다. 사후검정 결과 직무소진은 직업만족도가 낮을수록 직무만족도가 더 높았다. 또한 직무소진은 업무강도가 높은 경우가 적절하거나 적은 경우보다 직무만족도가 더 높았다. 대상자의 이직의도는 부서 이동 경험 $(\mathrm{t}=2.55, \mathrm{p}=.013)$, 간호사당 환자 수 $(\mathrm{F}=2.82, \mathrm{p}=.046)$, 희망부서 여부 $(\mathrm{t}=-3.01, \mathrm{p}=.004)$ 및 직업만족도 $(\mathrm{F}=6.93, \mathrm{p}<.001)$ 에서 유의한 차이가 있었다. 사후검정 결과 이직의도는 직업 만족도가 낮을수록 이직의도가 높았다[Table 3].

[표 3] 일반적 특성에 따른 조직몰입, 직무소진, 이직의도의 차이

[Table 3] Differences of Organizational Immersion, Job Burnout and Turnover Intention according to Characteristics of Participants $(\mathrm{N}=68)$

\begin{tabular}{|c|c|c|c|c|c|c|c|}
\hline \multirow[t]{2}{*}{ Variables } & \multirow[t]{2}{*}{ Categories } & \multicolumn{2}{|c|}{$\begin{array}{l}\text { Organizational } \\
\text { Immersion }\end{array}$} & \multicolumn{2}{|c|}{ Job Burnout } & \multicolumn{2}{|c|}{ Turnover Intention } \\
\hline & & $\mathbf{M} \pm \mathbf{S D}$ & $\operatorname{tor} F(p)$ & $\mathbf{M} \pm \mathbf{S D}$ & t or $F(p)$ & $\mathbf{M} \pm \mathbf{S D}$ & t or $F(p)$ \\
\hline \multirow{2}{*}{ Gender } & Male & $3.8 \pm 0.6$ & \multirow{2}{*}{$\begin{array}{c}0.99 \\
(.328)\end{array}$} & $2.0 \pm 0.8$ & \multirow{2}{*}{$\begin{array}{l}-1.94 \\
(.057)\end{array}$} & $2.3 \pm 1.0$ & \multirow{2}{*}{$\begin{array}{l}-1.36 \\
(.177)\end{array}$} \\
\hline & Female & $3.5 \pm 0.5$ & & $2.7 \pm 0.7$ & & $2.8 \pm 0.8$ & \\
\hline \multirow{6}{*}{$\begin{array}{l}\text { Clinical career } \\
\text { (Month) }\end{array}$} & 1 & $3.7 \pm 0.6$ & \multirow{6}{*}{$\begin{array}{c}1.51 \\
(.200)\end{array}$} & $2.4 \pm 0.8$ & \multirow{6}{*}{$\begin{array}{l}1.65 \\
(.160)\end{array}$} & $2.5 \pm 0.9$ & \multirow{6}{*}{$\begin{array}{c}2.10 \\
(.078)\end{array}$} \\
\hline & 2 & $3.2 \pm 0.6$ & & $3.2 \pm 0.7$ & & $3.4 \pm 0.9$ & \\
\hline & 3 & $3.6 \pm 0.4$ & & $2.8 \pm 0.3$ & & $2.8 \pm 0.6$ & \\
\hline & 4 & $3.5 \pm 0.4$ & & $2.8 \pm 0.7$ & & $2.8 \pm 0.4$ & \\
\hline & 5 & $3.4 \pm 0.6$ & & $2.8 \pm 0.6$ & & $3.2 \pm 0.6$ & \\
\hline & 6 & $3.3 \pm 0.6$ & & $2.5 \pm 0.5$ & & $2.6 \pm 1.0$ & \\
\hline \multirow{2}{*}{$\begin{array}{l}\text { Exprience of } \\
\text { working unit } \\
\text { change (Time) }\end{array}$} & Yes & $3.1 \pm 0.4$ & \multirow{2}{*}{$\begin{array}{l}-3.03 \\
(.003)\end{array}$} & $2.8 \pm 0.8$ & \multirow{2}{*}{$\begin{array}{c}0.92 \\
(.360)\end{array}$} & $3.3 \pm 0.7$ & \multirow{2}{*}{$\begin{array}{c}2.55 \\
(.013)\end{array}$} \\
\hline & No & $3.6 \pm 0.5$ & & $2.6 \pm 0.7$ & & $2.7 \pm 0.8$ & \\
\hline \multirow{4}{*}{$\begin{array}{l}\text { Number of } \\
\text { patients per } \\
\text { nurse }\end{array}$} & $<10$ & $3.4 \pm 0.5$ & \multirow{4}{*}{$\begin{array}{l}2.05 \\
(.116)\end{array}$} & $2.6 \pm 0.7$ & \multirow{4}{*}{$\begin{array}{l}0.96 \\
(.417)\end{array}$} & $2.8 \pm 1.0$ & \multirow{4}{*}{$\begin{array}{c}2.82 \\
(.046)\end{array}$} \\
\hline & $10 \sim 19$ & $3.4 \pm 0.4$ & & $2.9 \pm 0.7$ & & $3.1 \pm 0.6$ & \\
\hline & $20 \sim 29$ & $3.7 \pm 0.5$ & & $2.6 \pm 0.7$ & & $2.4 \pm 0.7$ & \\
\hline & $29<$ & $2.4 \pm 0.5$ & & $2.4 \pm 0.5$ & & $2.6 \pm 0.4$ & \\
\hline \multirow{2}{*}{ Type of Duty } & Shift & $3.5 \pm 0.5$ & \multirow{2}{*}{$\begin{array}{l}-0.27 \\
(.790)\end{array}$} & $2.7 \pm 0.7$ & \multirow{2}{*}{$\begin{array}{l}-0.53 \\
(.602)\end{array}$} & $2.8 \pm 0.8$ & \multirow{2}{*}{$\begin{array}{l}1.30 \\
(.199)\end{array}$} \\
\hline & Non-shift & $3.6 \pm 0.2$ & & $2.5 \pm 0.9$ & & $2.3 \pm 0.8$ & \\
\hline \multirow{2}{*}{$\begin{array}{c}\text { Working } \\
\text { department }\end{array}$} & Ward & $3.6 \pm 0.5$ & \multirow{2}{*}{$\begin{array}{c}0.66 \\
(.689)\end{array}$} & $2.7 \pm 0.7$ & \multirow{2}{*}{$\begin{array}{c}0.81 \\
(.950)\end{array}$} & $2.8 \pm 0.7$ & \multirow{2}{*}{$\begin{array}{c}0.26 \\
(.800)\end{array}$} \\
\hline & Special part & $3.5 \pm 0.5$ & & $2.7 \pm 0.7$ & & $2.8 \pm 0.9$ & \\
\hline \multirow{2}{*}{$\begin{array}{c}\text { Wanted present } \\
\text { department }\end{array}$} & Yes & $3.7 \pm 0.4$ & \multirow{2}{*}{$\begin{array}{c}2.49 \\
(.015)\end{array}$} & $2.6 \pm 0.7$ & \multirow{2}{*}{$\begin{array}{l}-0.81 \\
(.421)\end{array}$} & $2.5 \pm 0.7$ & \multirow{2}{*}{$\begin{array}{l}-3.01 \\
(.004)\end{array}$} \\
\hline & No & $3.4 \pm 0.5$ & & $2.7 \pm 0.7$ & & $3.0 \pm 0.8$ & \\
\hline Job satisfaction & Dissatisfieda & $2.8 \pm 0.6$ & 13.71 & $3.3 \pm 0.6$ & 3.90 & $3.9 \pm 0.7$ & 6.93 \\
\hline
\end{tabular}




\begin{tabular}{|c|c|c|c|c|c|c|c|}
\hline & Neutralb & $3.4 \pm 0.4$ & $\begin{array}{c}(<.001) \\
\mathrm{a}<\mathrm{b}<\mathrm{c}\end{array}$ & $2.9 \pm 0.6$ & $\begin{array}{c}(<.001) \\
a>b>c\end{array}$ & $3.0 \pm 0.7$ & $\begin{array}{l}(<.001) \\
a>b>c\end{array}$ \\
\hline & Satisfiedc & $3.8 \pm 0.5$ & & $2.3 \pm 0.6$ & & $2.3 \pm 0.7$ & \\
\hline \multirow{3}{*}{$\begin{array}{c}\text { Heavy } \\
\text { workload }\end{array}$} & too mucha & $2.5 \pm 0.6$ & \multirow{3}{*}{$\begin{array}{c}4.27 \\
(.018) \\
\mathrm{a}<\mathrm{c}<\mathrm{b}\end{array}$} & $4.3 \pm 0.0$ & \multirow{3}{*}{$\begin{array}{c}8.18 \\
(.001) \\
a>b, c\end{array}$} & $3.8 \pm 0.7$ & \multirow{3}{*}{$\begin{array}{c}2.82 \\
(.067)\end{array}$} \\
\hline & Quite a lotb & $3.6 \pm 0.5$ & & $2.6 \pm 0.6$ & & $2.8 \pm 0.7$ & \\
\hline & Appropiatec & $3.5 \pm 0.5$ & & $2.5 \pm 0.7$ & & $2.5 \pm 1.0$ & \\
\hline \multirow{3}{*}{$\begin{array}{c}\text { Day off } \\
\text { selection }\end{array}$} & I don't think soa & $3.4 \pm 0.6$ & \multirow{3}{*}{$\begin{array}{c}4.35 \\
(.017) \\
a>b\end{array}$} & $2.8 \pm 0.7$ & \multirow{3}{*}{$\begin{array}{c}0.90 \\
(.411)\end{array}$} & $2.9 \pm 0.9$ & \multirow{3}{*}{$\begin{array}{c}1.02 \\
(.366)\end{array}$} \\
\hline & Be averageb & $3.7 \pm 0.3$ & & $2.5 \pm 0.6$ & & $2.6 \pm 0.8$ & \\
\hline & That's rightc & $3.6 \pm 0.2$ & & $2.6 \pm 0.6$ & & $2.7 \pm 0.5$ & \\
\hline
\end{tabular}

Note. Scheffé test

\section{4 대상자의 조직몰입, 직무소진 및 이직의도 간의 상관관계}

본 연구에 참여한 대상자의 이직의도는 조직몰입 $(\mathrm{r}=-.71, \mathrm{p}<.001)$ 과 유의한 부적인 상관 관계를 보였으며, 직무소진 $(\mathrm{r}=-.46, \mathrm{p}<.001)$ 과 유의한 정적 상관관계를 보였다[Table 4].

[표 4] 조직몰입, 직무소진 및 이직의도 간의 상관관계

[Table 4] Correlations of Organizational Immersion and Job Burnout Affecting turnover Intention ( $\mathrm{N}=68)$

\begin{tabular}{|c|c|c|c|}
\hline \multirow{2}{*}{ Variables } & Turnover Intention & Organizational Immersion & Job Burnout \\
\cline { 2 - 4 } & \multicolumn{2}{|c|}{$\mathrm{r}(\mathrm{p})$} & \\
\hline Turnover Intention & 1 & \multicolumn{2}{|c|}{} \\
\hline $\begin{array}{c}\text { Organizational } \\
\text { Immersion }\end{array}$ & $\begin{array}{c}-.71 \\
(<.001)\end{array}$ & 1 & 1 \\
\hline Job Burnout & $\begin{array}{c}.46 \\
(<.001)\end{array}$ & $\begin{array}{c}-.42 \\
(<.001)\end{array}$ & 1 \\
\hline
\end{tabular}

\section{5 신입간호사의 이직의도에 미치는 영향요인}

본 연구에 참여한 신입간호사의 메타인지 영향요인을 파악하기 위해 다중회귀 분석을 실시한 결과는 [Table 5]와 같다. 상관관계 분석에서 상관성이 있는 것으로 확인된 변수 2 개(조직몰입, 직무소진)를 독립변수로 투입하였다. 회귀분석의 가정을 검정한 결과 모든 조건을 충족하는 것으로 나타났다. 독립변수의 자기상관에 대하여 오차 자기상관에 대하여 검토한 결과, Durbin-Watson 통계량이 1.86 으로 나타나 오차항 자기상관이 없이 독립적이었고, 독립변수 간 공차한계는 0.1 이상, 분산팽창인자(Variance Inflation Factor, $\mathrm{VIF}$ 도 10 이하로 확인되어 다중 공선성의 문제가 없음을 확인하였다. 그 결과 신입간호사의 조직몰입과 소진은 이직의도에 유의한 영향요인으로 나타났다. 신입간호사의 이직의도에 가장 영향력을 크게 미치는 요인은 조직몰입( $\beta=-.62$, $\mathrm{p}<.001)$ 이었고, 그 다음으로는 직무소진 $(\beta=.19, \mathrm{p}=.043)$ 순이었다. 분석결과 이직의도 회귀모형은 통계적으로 유의하였고 $(\mathrm{F}=36.52, \mathrm{p}<.001)$, 모형의 설명력을 나타내는 수정된 결정계수(Adj. $R^{2}$ )는 .52 로 설명력은 $52 \%$ 였다. 
[표 5] 신입간호사의 이직의도에 미치는 영향요인

[Table 5] Fectors Affecting New Nurses Turnover Intention ( $\mathrm{N}=68)$

\begin{tabular}{|c|c|c|c|c|c|c|c|}
\hline Variables & $\mathbf{B}$ & $\mathbf{S E}$ & $\boldsymbol{\beta}$ & $\mathbf{t}$ & $\mathbf{p}$ & \multicolumn{2}{|c|}{ Multicollinearity } \\
\cline { 5 - 8 } (Constant) & 5.62 & .70 & & 7.99 & $<.001$ & & \\
\hline $\begin{array}{c}\text { Organizational } \\
\text { Immersion }\end{array}$ & -.98 & .15 & -.62 & -6.65 & $<.001$ & .82 & 1.22 \\
\hline Job Burnout & .23 & .11 & .19 & 2.06 & .043 & .82 & 1.22 \\
\hline \multicolumn{8}{|c|}{$\mathrm{R}^{2}=.53$, Adj. $\mathrm{R}^{2}=.52, \mathrm{~F}=36.52, \mathrm{p}<.001$} \\
\hline
\end{tabular}

\section{4. 논의}

간호사의 이직은 병원의 안전하고 효과적인 의료서비스 제공을 저해하기 때문에 신입간호사 시기부터 이직의도를 파악하는 것이 중요하다. 본 연구에서는 6개월 이하의 신입간호사가 7 15개월 경력의 신입간호사보다 이직의도가 더 높았다는 선행연구를 토대로 6개월 이하 신입간호사를 대상으로 조직몰입, 직무소진 및 이직의도 정도를 살펴보고 이들 변인 간의 관계에 대하여 파악한 후 이직의도의 영향요인을 규명하여 추후 신입간호사의 이직의도 감소 방안을 모색하는데 기초자료로 활용하고자 시행하였다. 본 연구의 주요 결과를 토대로 한 논의는 다음과 같다.

본 연구에서 신입간호사의 조직몰입은 평균 $3.5 \pm 0.5$ 점(범위 1 5점)이었으며 측정도구가 달라 직접적인 비교는 어려우나 12 개월 미만의 간호사를 대상으로 Han 등[9]의 연구에서는 $3.0 \pm 0.73$ 점이었고 종합병원 간호사를 대상으로 한 $\operatorname{Jin}$ 와 $\operatorname{Kim}[22]$ 의 연구에서는 $2.90 \pm 0.58$ 점(범위 1 5점)이었다. 본 연구에서 신입간호사의 직무소진은 평균 $2.7 \pm 0.7$ 점(범위 $0 \sim 6$ 점)이었으며 측정도구가 달라 직접적인 비교는 어려우나 6 개월 이상 간호사를 대상으로 한 $\mathrm{Kim}$ 등[23]의 연구에서는 $2.78 \pm 0.57$ 점이었다. 본 연구에서 신입간호사의 이직의도는 평균 $2.8 \pm 0.8$ 점(범위 1 1 5점)으로 종합점수로 환산 시 $16.8 \pm 4.8$ 점 이었으며 종합병원 신입간호사를 대상으로 한 $\mathrm{Ji}$ 와 $\mathrm{Kim}[8]$ 의 연구에서 6 개월 이하 신입간호사는 $17.82 \pm 3.69$ 점, 7 15개월 신입간호사는 $19.65 \pm 3.02$ 점으로 나타났다. 이를 통해 6개월 이하 신입간호사의 조직몰입, 직무소진 및 이직의도 정도는 6개월 이상의 임상간호사와 큰 차이가 없음을 알 수 있었다. 본 연구의 대상자의 일반적 특성에 따른 조직몰입의 차이는 부서 이동 경험, 희망부서 여부, 직업만족도, 업무강도 및 휴일 선택권에서 유의한 차이가 있었다. 사후검정 결과 조직몰입은 직업만족도가 높을수록, 업무강도가 적절한 경우보다는 낮은 경우에, 낮은 경우보다는 높은 경우에서 그리고 휴일 선택권이 보통인 경우보다 전혀 선택권이 없을수록 더 높았다. Park과 Kim [24]의 연구에서 임상 간호사에게 있어 조직몰입은 임상경력에 따라 유의한 차이가 있었는데 본 연구의 대상자는 임상경력이 6개월 이하로 짧아 임상경력에 따른 조직몰입의 차이보다는 부서 이동 경험에 따라 차이가 나타난 것으로 사료된다. 본 연구의 6 개월 이하 신입간호사에게 있어 부서이동 경험은 조직에 적응할 시간을 부족하게 만든 것으로 생각한다. 대상자의 직무소진은 근무부서, 직업만족도 및 업무강도에 따라 유의한 차이가 있었다. 사후검정 결과 직무소진은 직업만족도가 
낮을수록 더 높았으며, 업무강도가 높은 경우가 적절하거나 적은 경우보다 직무만족도가 더 높았다. 이는 임상간호사들이 과다한 업무와 관련하여 소진을 경험했던 것처럼[14] 신입간호사들도 직업에 만족하지 못하고 과도한 직무에 노출될수록 직무소진 정도에 차이가 나타난 것으로 사료된다. 대상자의 이직의도는 부서 이동 경험, 간호사당 환자 수, 희망부서여부 및 직업만족도에서 유의한 차이가 있었다. 사후검정 결과 직업만족도가 낮을수록 이직의도가 높았다. Kim과 Lee[25]의 연구에서 간호사가 간호직에 '매우 불만족' 한 경우에서 이직의도가 가장 낮은 것으로 나타나 신입간호사를 포함하여 자신의 직업에 만족하지 못하면 이직의도가 높음을 알 수 있었다. 본 연구에 참여한 대상자의 이직의도는 조직몰입, 직무소진과 유의한 상관관계를 보였다. 먼저 조직몰입 높을수록 이직의도는 낮아지는 것으로 확인되었다. Jeoung 과 $\mathrm{Kim}[26]$ 의 연구에서 신입간호사의 조직몰입과 이직의도는 부적 상관관계를 나타냈다. 조직몰입은 조직의 구성원으로 남아있으려는 강한 욕구로서[16] 조직몰입이 높아질수록 이직의도가 낮아진 것으로 사료된다. 본 연구에서 신입간호사의 직무소진이 높아질수록 이직의도가 낮아지는 것으로 확인되었다. 대학병원 간호사를 대상으로 한 Kim과 Seomun[15]의 연구에서 소진과 이직의도는 상관관계가 있는 것으로 나타나 본 연구의 결과를 지지하였다. 이직에 영향을 미치는 요인으로 소진은 직무스트레스와 관련하여 반복적인 정서적 압박의 결과로 발생하며 무기력, 절망감, 부정적 자아 개념 및 자기 직업, 타인에 대한 강한 부정적인 태도를 가져오는 현상이며[25] 이는 이직의도와도 관련성이 나타난 것으로 사료된다.

본 연구의 결과 신입간호사의 이직의도에 가장 영향력을 크게 미치는 요인은 조직몰입이었고, 그 다음으로는 직무소진 순이었으며 설명력은 $52 \%$ 였다. 신입간호사를 대상으로 한 Kim과 Lee[13]의 연구에서도 조직몰입이 이직의도에 가장 큰 영향력을 미치는 변인으로 나타났다. 또한 Han 등[9]의 연구에서 신입간호사의 이직의도에 영향을 미치는 요인은 조직몰입, 소진, 스트레스, 현 병동 근무기간, 조직문화, 자기효능감, 병상수 순으로 나타나 본 연구의 결과를 지지했다. 신입간호사에게 조직몰입은 조직에 적응하기 위해 자신에게 긍정적인 동기를 부여하고 의욕을 북돋아 높을수록 조직에 잘 적응하며 조직의 목표를 달성하고자 노력하기 때문에 이직의도에 부정적인 영향을 미친 것으로 사료된다. 신입간호사는 대학을 졸업하고 병원이라는 새로운 환경에 적응하면서 정서적 압박과 스트레스의 결과로 더 이상 업무에서 오는 스트레스를 감당하기 어렵다고 느끼는 소진을 경험하게 되며 이러한 직무소진이 지속될 경우 이직을 생각하게되는 것으로 보인다. 따라서 신입간호사의 이직의도를 낮추기 위해서는 신입간호사가 희망하는 부서로 배치를 우선적으로 하고 현실충격에서 벗어나 업무에 적응하는 기간동안 업무량을 조절하여 새로운 환경에 잘 적응할 수 있도록 도와 조직몰입을 높여주는 것이 필요할 것으로 사료된다. 또한 신입간호사의 업무적응을 위한 프리셉터 교육기간이 지난 후에도 일정기간동안 업무에 숙달할 때까지 지속적인 피드백과 업무량을 조절하여 소진을 예방하고 프리셉터 및 선배 간호사와의 소통의 장을 열어 직무소진을 낮추기 위한 프로그램 개발이 필요할 것으로 생각한다. 


\section{5. 결론 및 제언}

본 연구는 신입간호사의 이직의도에 영향을 미치는 요인을 파악하기 위해 시도된 서술적 상관관계 조사연구이다. 연구결과 신입간호사의 이직의도에는 조직몰입과 직무소진 모두 영향력을 미치며 조직몰입이 더 큰 영향력을 미치는 것을 확인되었다. 따라서 신입간호사의 이직의도를 감소시키기 위해서는 신입간호사의 조직몰입을 높이기 위한 프로그램을 개발하고 직무소진을 낮추기 위한 방안을 적용하는 것이 필요할 것으로 생각된다. 본 연구는 일개병원 신입간호사 68 명을 대상으로 하였으므로 연구결과를 일반화하기에는 제한이 있다. 따라서 지역, 병원규모, 부서, 근무환경 등 여러 환경적인 측면을 반영하여 이직의도에 영향을 미치는 변인을 확인하기 위한 반복적인 연구가 필요하다. 본 연구의 결과 조직몰입이 가장 영향력이 있는 요인으로 확인되었으므로, 신입간호사의 조직몰입을 증진시키기 위한 중재 및 지지체계를 구축하여 이직의도 감소에 미치는 영향력을 확인하기 위한 연구를 제언한다.

\section{References}

[1] J. S. Lee, H. M. Co, H. J. Chung, H. L. Kim, Working Conditions of the National Health Care Workers -Wages, Work Conditions and Environment-,The Journal of Labor Studies, (2016), Vol.33, pp.169-197.

[2] T. W. Lee, K. H. Kang, Y. K. Ko, S. H. Cho, E. Y. Kim, Issues and Challenges of Nurse Workforce Policy: A Critical Review and Implication, Journal of Korean Academy of Nursing Administration, (2014), Vol.20, No.1, pp.106-116, https://doi.org/10.11111/jkana.2014.20.1.106

[3] A Survey on the Current Status of Hospital Nursing Personnel, Hospital Nurses Association, (2018), pp.69-98.

[4] J. S. Cho, M. H. Kim, S. R. Kim, W. I. Park, J. O. Cho, M. H. Ko, A Survey on the Current Status of Hospital Nursing Personnel, Hospital Nurses Association, (2019), pp.137-163.

[5] S. Y. Park, Issues and Challenges of Nursing Workforce Supply to Improve the Quality of Health Care Services, Korean Journal of Converging Humanities, (2018), Vol.6, No.1, pp.31-54, http://dx.doi.org/10.14729/converging.k.2018.6.1.31

[6] J. H. Park, Turnover Reduction Strategy of New Graduate Nurses, Asia-pacific Journal of Multimedia Services Convergent with Art, Humanities, and Sociology, (2017), Vol.7, No.8, pp.833-842.

[7] S. Y. Lee, E. J. Oh, K. M. Sung, The Experiences of Turnover Intention in Early Stage Nurses, Journal of East-West Nursing Research, (2013), Vol.19, No.2, pp.168-176, https://doi.org/10.14370/jewnr.2013.19.2.168

[8] E. A. Ji, J. S. Kim, Factor Influencing New Graduate Nurses Turnover Intention according to Length of Service, Journal of Korean Academy of Nursing Administration, (2018), Vol.24, No.1, pp.51-60, https://doi.org/10.11111/jkana.2018.24.1.51

[9] S. S. Han, S. I. Sohn, N. E. Kim, New Nurse Turnover Intention and Influencing Factors, Journal of Korean Academy of Nursing, (2009), Vol.39, No.6, pp.878-887, https://doi.org/10.4040/jkan.2009.39.6.878

[10] S. J. Moon, S. S. Han, A Predictive Model on Turnover Intention of Nurses in Korea, Journal of Korean Academy of Nursing, (2011), Vol.41, No.5, pp.633-641, https://doi.org/10.4040/jkan.2011.41.5.633

[11] Y. O. Lee, J. Y. Kang, Related Factors of Turnover Intention among Korean Hospital Nurses: A Systematic Review and Meta-Analysis, Korean Journal of Adult Nursing, (2018), Vol.30, No.1, pp.1-17, https://doi.org/10.7475/kjan.2018.30.1.1

[12] Y. S. Yang, ICU New Nurses' Job Stress, Job Satisfaction, Organizational Commitment and Turnover Intention, Ewha Womans University, (2013), Vol.25, No.2, pp.47-58. 
[13] J. H. Kim, M. H. Lee, Factors Affecting the Turnover Intention of the New Graduated Nurses, Journal of the Korea Academia-Industrial cooperation Society, (2020), Vol.21, No.5, pp.312-319, https://doi.org/10.5762/KAIS.2020.21.5.312

[14] J. I. Kim, H. M. Son, I. H. Park, H. J. Shin, J. H. Park, M. O. Cho, S. U. Kim, M. O. Yu, Phenomenological Study on Burnout Experience of Clinical Nurses Who have Turnover Intention, Korean Journal of Women Health Nursing, (2015), Vol.21, No.4, pp.297-307, DOI: https://doi.org/10.4069/kjwhn.2015.21.4.297

[15] M. R. Kim, G. A. Seomun, Relationships among Burnout, Job Satisfaction, Organizational Commitment and Turnover Intention to Resign in Hospital Nurses, Korean Journal of Occupational Health Nursing, (2013), Vol.22, No.2, pp.93101, UCI : G704-001949.2013.22.2.009

[16] R. T. Mowday, R, M. Steers, L, W. Porter, The Measurement of Organizational Commitment, Journal of Vocational Behavior, (1979), Vol.14, No.2, pp.224-247, https://doi.org/10.1016/0001-8791(79)90072-1

[17] H. K. Chung, The Determinants of Organizational Commitment of Hospital Nurses, Yonsei University, Master's thesis, (2006)

[18] C. Maslach, S. E. Jackson, The measurement of experienced burnout, Journal of Occupational Behavior, (1981), Vol.2, No.2, pp.99-113, https://doi.org/10.1002/job.4030020205

[19] H. Y. Choi, Perfectionism tendency, social support and burnout among counselors, Catholic University, Master's thesis, (2002)

[20] W. H. Mobley, Employee turnover: Causes, consequences, and control, Reading, MA: Addison-Wesley, (1982)

[21] M. R. Kim, Influential factors on turnover intention of nurses: The affect of nurse's organizational commitment and career commitment to turnover intention, Journal of Korean Academy of Nursing Administration, (2007), Vol.13, No.3, pp.335-344, UCI : G704-001792.2007.13.3.003

[22] S. H. Jin, J. H. Kim, Influence of Resilience and Perceived Individual and Organizational Support on Organizational Commitment among Hospital Nurses, Journal of Digital Convergence, (2017), Vol.15, No.5, pp.293-303, https://doi.org/10.14400/JDC.2017.15.5.293

[23] M. J. Kim, Y. S. Park, Y. H. Kwon, The Effects of Clinical Nurses' Resilience and Social Problem-Solving Ability on Burnout, Journal of the Korea Academia-Industrial cooperation Society, (2015), Vol.16, No.2, pp.1284-1291, https://doi.org/10.5762/KAIS.2015.16.2.1284

[24] G. J. Park, Y. N. Kim, Factors Influencing Organizational Commitment among Hospital Nurses, Journal of Korean Academy of Nursing Administration, (2010), Vol.16, No.3, pp.250-258, DOI: https://doi.org/10.11111/jkana.2010.16.3.250

[25] S. H. Kim, M. A. Lee, Effects of Emotional Labor and Communication Competence on Turnover Intention in Nurses, Journal of Korean Academy of Nursing Administration, (2014), Vol.20, No.3, pp.332-341, https://doi.org/10.11111/jkana.2014.20.3.332

[26] H. Y. Jeoung, S. Y. Kim, Effects of Nursing Professionalism and Job Involvement on Turnover Intention among New Graduate Nurses, Journal of Korean Academy of Nursing Administration, (2016), Vol.22, No.5, pp.531-539, DOI: https://doi.org/10.11111/jkana.2016.22.5.531 